\title{
Fluid Acoustic Properties of Improved Hydraulic Mufflers with Extended Necks
}

\author{
Fan Yang and Bin Deng \\ Department of Mechanical Engineering, Southwest Jiaotong University, Chengdu, China.
}

(Received 7 December 2016; accepted 7 August 2017)

The acoustic properties of three improved hydraulic mufflers with extended necks are investigated theoretically and experimentally. The effect of length and slope of the conical tube, and the perforations on the extended tube is studied on the resonance frequency and the insertion loss. The plane wave approach is used for the constant and the variable area tubes, while Sullivan and Peat's method is applied for the perforation tube unit. Theoretical predictions are compared with experiments for these three different hydraulic noise suppressors, which are fabricated. It is shown that the resonance frequency and the insertion loss characteristics may be controlled by the length and the slope of the conical tube and perforation porosity of the extended tube without changing the expansion chamber volume. Finally, the effect of the cross-sectional shape of the expansion chamber is investigated.

\section{NOMENCLATURE}

\begin{tabular}{ll}
$c$ & Speed of sound \\
$U$ & Velocity of mean flow \\
$k$ & Wave number \\
$p$ & Pressure pulsation \\
$p_{0}$ & Ambient pressure \\
$\rho$ & Density perturbation \\
$\rho_{0}$ & Ambient density \\
$u$ & Particle velocity \\
$v$ & Mass velocity \\
$x$ & Axial coordinate \\
$\beta$ & Bulk modulus \\
$Y$ & Characteristic impedance \\
$\zeta$ & Fluidic impedance \\
$j$ & Imaginary unit \\
$S$ & Cross section area \\
$t$ & Time domain; perforate tube thickness \\
$\eta$ & Slope of conical tube \\
$d_{0}$ & Inlet diameter of conical tube \\
$d_{l}$ & Outlet diameter of conical tube \\
$D$ & $d / d x$ \\
$\varsigma$ & Impedance of perforate \\
$V R$ & Velocity ratio \\
$f$ & As defined in Eq. (15) \\
$\nu$ & Radial velocity \\
$\sigma$ & Porosity of perforate \\
$d_{h}$ & Hole diameter \\
$d$ & Diameter of the perforated tube \\
$\Theta$ & As defined in Eq. (18) \\
$T$ & Transfer matrix \\
$\Omega$ & Control volume \\
$\Gamma$ & Control surface \\
$\hat{n}$ & Unit vector normal to $\Gamma$ \\
$d_{e}$ & Equivalent diameter of the chamber \\
$D / D t$ & Substantive derivative \\
\hline & Matrix of eigenvectors \\
\hline & Eigenvalue \\
\hline doiorg/10.20855/ijv.
\end{tabular}

$\begin{array}{ll}\text { Subscripts } & \\ 0 & \text { Equilibrium state } \\ s & \text { Isentropic process } \\ \text { Superscripts } & \\ \sim & \text { Perturbed quantity }\end{array}$

\section{INTRODUCTION}

The fundamental assumptions used in the formulation of the governing equations of motion for the resonators were as follows: ${ }^{1}$

1. the Reynolds number in the tube was low (smaller than 2000), which was called the laminar flow

2. The amplitude of pressure pulsation and related density in either tube or cavity was small, compared with the mean flow values

3. Gradients of temperature of the medium in the resonator were neglected;

4. In the case of a rigid-walled tube filled with a stationary ideal fluid, inviscid waves travel as plane waves.

The basic equations for this case were: ${ }^{3}$ mass continuity:

$$
\frac{\partial \tilde{\rho}}{\partial t}+\vec{\nabla} \cdot(\tilde{\rho} \tilde{\vec{u}})=0
$$

dynamical equilibrium:

$$
\tilde{\rho} \frac{D \tilde{\vec{u}}}{D t}+\vec{\nabla} \tilde{p}=\overrightarrow{0}
$$

energy equation:

$$
c_{0}^{2} \approx\left(\frac{d p}{d \rho}\right)_{s, 0}=\frac{1}{\beta_{s} \rho_{0}}=\frac{p}{\rho} ;
$$

Using the basic linearized form of Eq. (1), (2) and (3) yielded:

$$
\Delta p-\frac{1}{c_{0}^{2}} \frac{\partial^{2} p}{\partial t^{2}}=0
$$




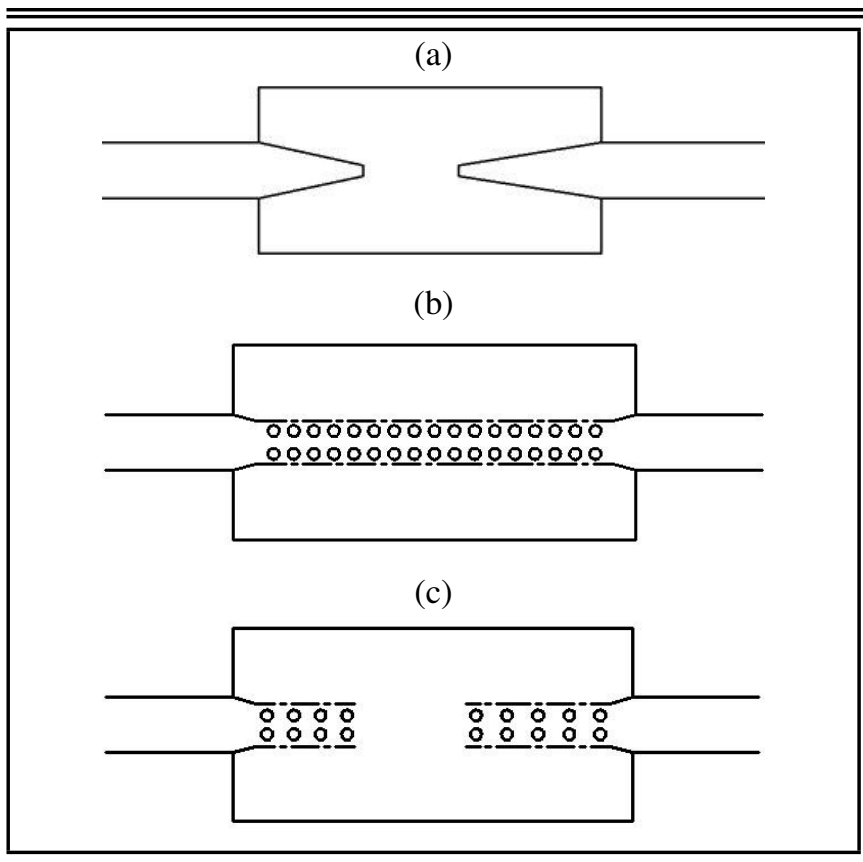

Figure 1. Schematics of improved hydraulic noise suppressor.

where

$$
\begin{aligned}
& \tilde{p}=p_{0}+p ; \\
& \tilde{u}=U_{0}+u ; \\
& \tilde{\rho}=\rho_{0}+\rho ;
\end{aligned}
$$

Nowadays, extended-tube expansion chamber attenuators are widely used in hydraulic systems to attenuate pressure pulsation. These configurations consisted of the straight-through type and the reversed-flow type. Generally speaking, straightthrough attenuators offer low resistance and thus maintain low pressure loss, however the attenuation ratio is not very effective. Reversed-type, on the other side, may increase attenuation, though at the cost of a higher-pressure loss. ${ }^{2}$ Consequently, improved structures were put forward, as shown in Fig. 1. An extended-tube expansion chamber (ETEC) muffler is known to be effectively used in the range of low frequencies and the length of the neck extension will shift the resonance frequency without changing the volume. ${ }^{11}$ Besides, the neck shape which included either variable cross-sectional area or perforations could change the acoustic properties of the hydraulic noise suppressor. The present work therefore concentrated on the effect of an extended neck (Fig. 1) on the ETEC behaviour. Finally, although many air silencer models include the mean flow speed as a Mach flow number, the flow speed in a hydraulic suppressor is generally much lower than the speed of sound in hydraulic oil, and could be ignored. ${ }^{16}$

This paper is divided into two pieces and the object is to

1. research theoretically and experimentally the pressure pulsation characteristics of an extended-tube pulsation attenuator with conical tubes and perforated elements; and

2. inspect the effects of tapering of the conical tubes, length of the extended-tubes, shape of the expansion chamber, and perforation of the extended-tubes on the attenuator behaviour. Results presented included insertion loss (IL) comparing this improved configuration with the corresponding expansion chamber resonator.

\section{THEORY}

Firstly, the fluidic filter, which is shown in Fig. 1(c), is divided into 9 units, as shown in Fig. 2.

\subsection{Solution for Uniform Tube Unit}

The solution to Eq. (4) in units 1, 5, and 9 could be written as: ${ }^{3}$

$$
\left[\begin{array}{c}
p_{r} \\
v_{r}
\end{array}\right]=\left[\begin{array}{cc}
\cos k_{0} l_{r} & j Y_{r} \sin k_{0} l_{r} \\
j / Y_{r} \sin k_{0} l_{r} & \cos k_{0} l_{r}
\end{array}\right]\left[\begin{array}{c}
p_{r-1} \\
v_{r-1}
\end{array}\right]
$$

where $r$ equalled 1,5 , and 9 .

\subsection{Solution for Conical Tube Unit}

The basic equations that governed the plane wave propagation along a conical tube were the same as Eq. (2) and Eq. (3), except for the mass continuity equation, which was governed by: $:^{3,4}$

$$
\frac{\partial \rho}{\partial t}+\rho_{0} \frac{\partial u}{\partial x}+\frac{u \rho_{0}}{S} \frac{d S}{d x}=0
$$

Figure 3 shows a conical tube with the diameter that was proportional to the distance from the hypothetical apex:

$$
S(x)=x^{2}
$$

Equations (2), (3), and (6) were associated with Eq. (7). Thus, the solutions for units 2 and 8 were:

$$
\left[\begin{array}{c}
p(0) \\
v(0)
\end{array}\right]=\left[\begin{array}{ll}
T_{11} & T_{12} \\
T_{21} & T_{22}
\end{array}\right]\left[\begin{array}{c}
p(l) \\
v(l)
\end{array}\right]
$$

where

$$
\begin{gathered}
T_{11}=\frac{d_{l}}{d_{0}} \cos \left(k_{0} l\right)-\frac{\eta}{k_{0} d_{0}} \sin \left(k_{0} l\right) ; \\
T_{12}=j Y(0) \frac{d_{0}}{d_{l}} \sin \left(k_{0} l\right) ; \\
T_{21}=\left\{\frac{j}{Y(0)} \frac{d_{l}}{d_{0}}\left(1+\frac{\eta^{2}}{k_{0}^{2} d_{0} d_{l}}\right) \sin \left(k_{0} l\right)\right. \\
\left.-\frac{j \eta}{k_{0} d_{0} Y(0)} \frac{d_{l}}{d_{0}}\left(1-\frac{d_{0}}{d_{l}}\right) \cos \left(k_{0} l\right)\right\} ; \\
T_{22}=\frac{\eta}{k_{0} d_{l}} \sin \left(k_{0} l\right)+\frac{d_{0}}{d_{l}} \cos \left(k_{0} l\right) ;
\end{gathered}
$$

\subsection{Solution for Open-Ended Two-Duct Perforated Elements Enclosed in a Circular Chamber}

The configuration of open-ended two-duct perforated elements is shown in Fig. 4. Before the derivation of governing equations, the mean flow in the chamber (designated by 2 in Fig. 4) was assumed to be zero. The gradient of the mean flow was neglected. ${ }^{6}$ 


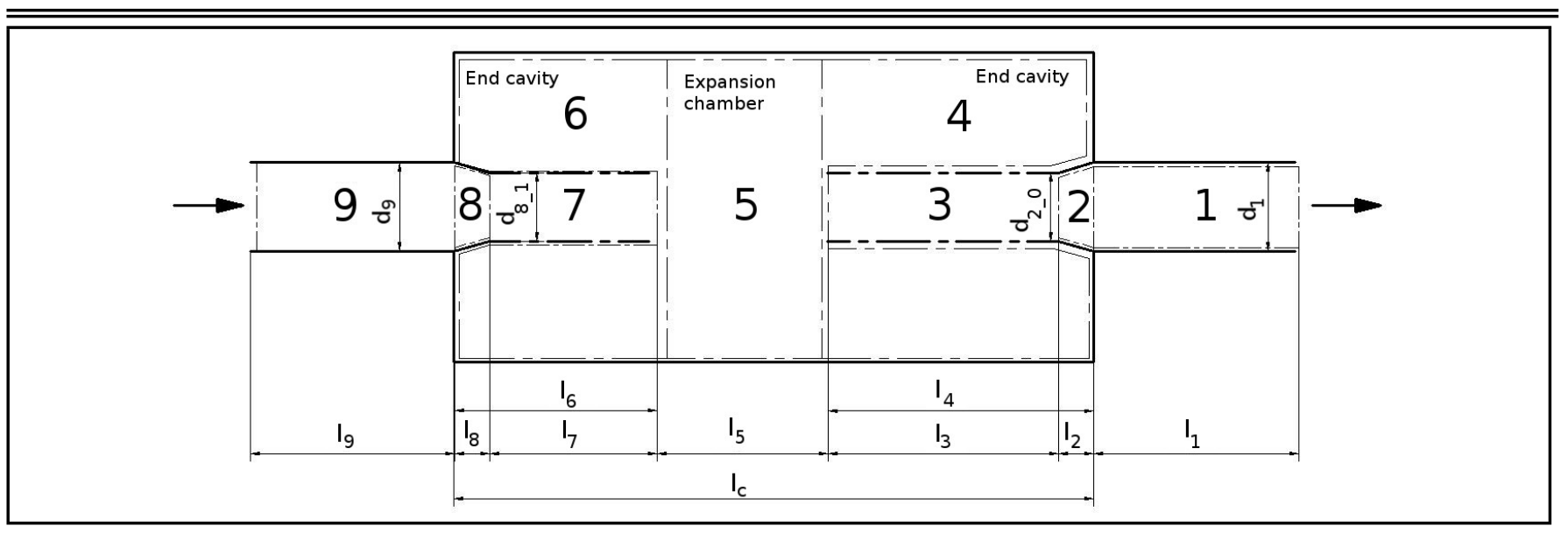

Figure 2. Line diagram of Fig. 1(c).

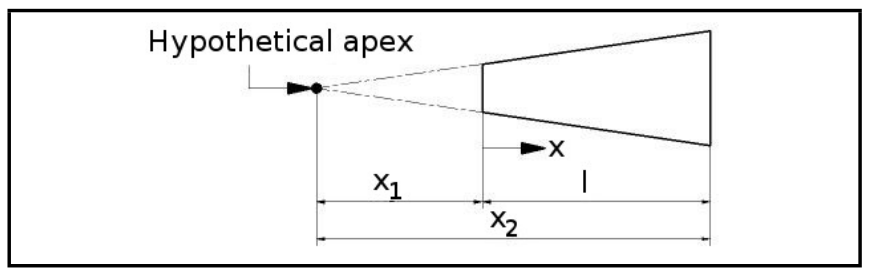

Figure 3. Configuration of conical tube.

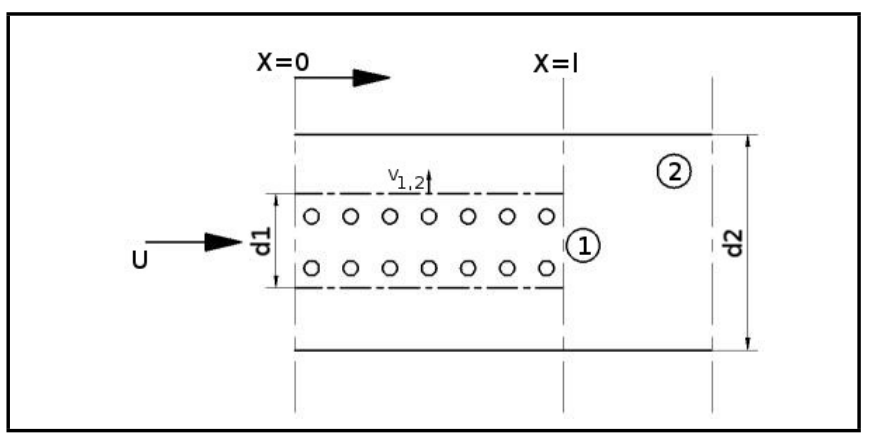

Figure 4. Open-ended two-duct perforated elements.

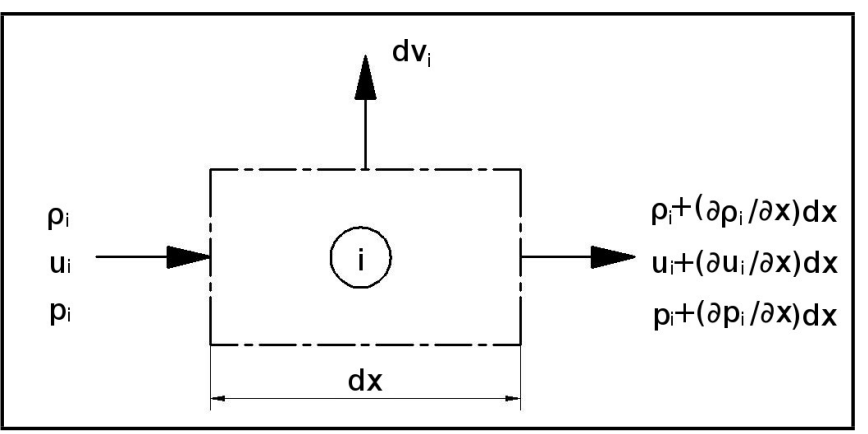

Figure 5. Control volumes in muffler.

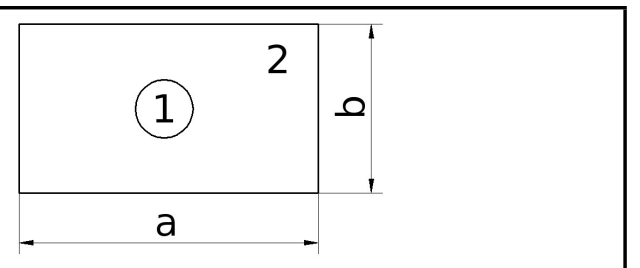

Figure 6. Rectangular cross-section of a chamber and a circular tube.
Consider two control volumes of length $\mathrm{dx}$, as shown in Fig. 5. In this section, the cross section of the tube and chamber was circular. The governing equations were followed by those of Sullivan $^{7,8}$ and Peat. ${ }^{8}$

Integrating Eq. (1) over a finite control volume $\Omega$ (as shown in Fig. 5) and applying the divergence theorem, and then linearing the governing equations yielded: ${ }^{2-6}$

$$
\frac{\partial \rho_{i}}{\partial t}+U_{i} \frac{\partial \rho_{i}}{\partial x}+\rho_{0} \frac{\partial u_{i}}{\partial x}+\rho_{0} f_{i}=0, \quad i=1,2 ;
$$

for the mass continuity equation and

$$
\rho_{0} \frac{\partial u_{i}}{\partial t}+\rho_{0} U_{i} \frac{\partial u_{i}}{\partial x}+\frac{\partial p_{i}}{\partial x}=0, \quad i=1,2
$$

for the momentum equation. Where

$$
\begin{gathered}
f_{1}=\frac{4}{d_{1}} \nu_{1,2} ; \\
f_{2}=-\frac{4 d_{1}}{d_{2}^{2}-d_{1 e}^{2}} \nu_{1,2} ; \\
d_{1 e}=d_{1}+2 t ;
\end{gathered}
$$

because of the isentropic relationship, the energy equation was also Eq. (3). On account of uniform perforations in a duct of a constant cross section, ${ }^{1}$

$$
\nu_{1,2}=\frac{p_{1}-p_{2}}{\rho_{0} c_{0} \varsigma}
$$

the empirical formula for the perforate impedance in the stationary medium, 1,8

$$
\varsigma=\left[6 \times 10^{-3}+j k_{0}\left(t+0.75 d_{h}\right)\right] / \sigma
$$

The decoupling of the above equations and their pursuant solutions yielded:

$$
\left\{\begin{array}{c}
p_{1}(0) \\
\rho_{0} c_{0} u_{1}(0) \\
p_{2}(0) \\
\rho_{0} c_{0} u_{2}(0)
\end{array}\right\}=[\Theta]\left\{\begin{array}{c}
p_{1}(l) \\
\rho_{0} c_{0} u_{1}(l) \\
p_{2}(l) \\
\rho_{0} c_{0} u_{2}(l)
\end{array}\right\}
$$

combined with rigid boundary conditions,

$$
\frac{\rho_{0} c_{0} u_{2}(0)}{p_{2}(0)}=-j \tan \left(k_{0} l_{a}\right) ;
$$




$$
\frac{\rho_{0} c_{0} u_{2}(l)}{p_{2}(l)}=-j \tan \left(k_{0} l_{b}\right)
$$

and then yielded,

$$
\left\{\begin{array}{c}
p_{1}(0) \\
\rho_{0} c_{0} u_{1}(0)
\end{array}\right\}=\left[\begin{array}{cc}
T_{11} & T_{12} \\
T_{21} & T_{22}
\end{array}\right]\left\{\begin{array}{c}
p_{1}(l) \\
\rho_{0} c_{0} u_{1}(l)
\end{array}\right\}
$$

where $T_{11}-T_{22}$ are defined on top of the next site.

\subsection{Solution for Open-Ended Two-Duct Perforated Elements in a Rectangular or Square Chamber}

In this section, the tube was circular, however the crosssection of the expansion chamber and the end cavity was rectangular or square. For the theoretical treatment, rectangular and square cross sections were replaced by circular ducts of equal cross-sectional perimeters.

Integration of Eq. (1) and Eq. (2) yielded

$$
\left\{\begin{array}{c}
\frac{\partial}{\partial t} \oiiint_{\Omega} \tilde{\rho}_{i} d \Omega+\oiint_{\Gamma} \tilde{\rho}_{i} \tilde{\vec{u}}_{i} \cdot \hat{n} d \Gamma=0, \quad i=1,2 ; \\
\oiiint_{\Omega} \frac{\partial \tilde{\vec{u}}_{i}}{\partial t} d \Omega+\frac{1}{2} \oiint_{\Gamma} \tilde{\vec{u}}_{i} \cdot \tilde{\overrightarrow{\vec{u}}}_{i} \hat{n} d \Gamma+\oiiint_{\Omega} \frac{1}{\tilde{\rho}_{i}} \vec{\nabla} \tilde{p}_{i} d \Gamma=\overrightarrow{0}, \quad i=1,2 ;
\end{array}\right.
$$

Then, the linearized governing equations were similar to Eq. (14) and (15), however the equivalent diameter of the rectangular cross-section was that of:

$$
d_{e}=2 \cdot \sqrt{\frac{a b}{\pi}} .
$$

For the time harmonic motion and above assumptions, the coupled equations for the tube and chamber became:

$$
\left[\begin{array}{cc}
D^{2}+\alpha_{2} & \alpha_{4} \\
\alpha_{6} & D^{2}+\alpha_{8}
\end{array}\right]\left\{\begin{array}{l}
p_{1} \\
p_{2}
\end{array}\right\}=\left\{\begin{array}{l}
0 \\
0
\end{array}\right\}
$$

where

$$
\begin{gathered}
\alpha_{2}=\left(k_{0}^{2}-\frac{4 j k_{0}}{d_{1} \varsigma}\right) ; \\
\alpha_{4}=\frac{4 j k_{0}}{d_{1} \varsigma} ; \\
\alpha_{6}=\frac{4 j k_{0} d_{1}}{\left(d_{2}^{2}-d_{1 e}^{2}\right) \varsigma} ; \\
\alpha_{8}=k_{0}^{2}-\frac{4 j k_{0} d_{1}}{\left(d_{2}^{2}-d_{1 e}^{2}\right) \varsigma} ; \\
\alpha_{1}=\alpha_{3}=\alpha_{5}=\alpha_{7}=0 ;
\end{gathered}
$$

Notwithstanding, the decoupling approach was the same as section 2.3, the matrix was that of:

$$
[\Lambda(x)]=\left[\begin{array}{cccc}
\Psi_{31} e^{\lambda_{1} x} & \Psi_{32} e^{\lambda_{2} x} & \Psi_{33} e^{\lambda_{3} x} & \Psi_{34} e^{\lambda_{4} x} \\
\frac{-\Psi_{11} e^{\lambda_{1} x}}{j k_{0}} & \frac{-\Psi_{12} e^{\lambda_{2} x}}{j k_{0}} & \frac{-\Psi_{13} e^{\lambda_{3} x}}{j k_{0}} & \frac{-\Psi_{14} e^{\lambda_{4} x}}{j k_{0}} \\
\Psi_{41} e^{\lambda_{1} x} & \Psi_{42} e^{\lambda_{2} x} & \Psi_{43} e^{\lambda_{3} x} & \Psi_{44} e^{\lambda_{4} x} \\
\frac{-\Psi_{21} e^{\lambda_{1} x}}{j k_{0}} & \frac{-\Psi_{22} e^{\lambda_{2} x}}{j k_{0}} & \frac{-\Psi_{23} e^{\lambda_{3} x}}{j k_{0}} & \frac{-\Psi_{24} e^{\lambda_{4} x}}{j k_{0}}
\end{array}\right]
$$

Table 1. Properties of the hydraulic fluid.

\begin{tabular}{||c|c|}
\hline Density $\left(\mathrm{kg} \cdot \mathrm{m}^{-3}\right)$ & 866 \\
\hline Sound Speed $\left(\mathrm{m} \cdot \mathrm{s}^{-1}\right)$ & 1400 \\
\hline Kinematic Viscosity $(c S t)$ at $40^{\circ} \mathrm{C}$ & 46.0 \\
\hline
\end{tabular}

\section{EXPERIMENTS AND DISCUSSION}

A general block diagram of this configuration is shown in Fig. 7.

For the hydraulic noise suppressor of Fig. 2, combining above overall four-pole parameters transfer matrices for each unit got the relation:

$$
\left\{\begin{array}{l}
p_{n+1} \\
v_{n+1}
\end{array}\right\}=\left[\begin{array}{cc}
1 & 0 \\
1 / Z_{n+1} & 1
\end{array}\right]\left[T_{\text {overall }}\right]\left[\begin{array}{cc}
1 & Z_{0} \\
0 & 1
\end{array}\right]\left\{\begin{array}{c}
0 \\
v_{0}
\end{array}\right\}
$$

After the multiplication of all the matrices in Eq. (32), the resultant matrix yielded:

$$
\left\{\begin{array}{c}
p_{n+1} \\
v_{n+1}
\end{array}\right\}=\left[\begin{array}{ll}
R_{11} & R_{12} \\
R_{21} & R_{22}
\end{array}\right]\left\{\begin{array}{c}
0 \\
v_{0}
\end{array}\right\}
$$

Assuming that $Z_{10} \rightarrow \infty$, insertion loss (IL) was then calculated by: $:^{3,10}$

$$
I L=20 \log \left|\frac{Z_{n+1}}{Z_{n+1}+Z_{0}} V R_{n+1}\right|=20 \log \left|R_{22}\right| ;
$$

\subsection{Experiments Setup}

The parameters of hydraulic fluid used in these experiments are shown in Table 1 and the frequencies of interest were from 0 to $2000 \mathrm{~Hz}$. Considering that the wall of the tube is adiabatic, there was no heat exchange between the environment and the fluid in the duct.

Figures 1(a), (b), and (c) had been fabricated with fixed size:

$$
\begin{gathered}
d_{9}=d_{1}=0.0386 m \\
l_{9}=l_{1}=0.074 m \\
l_{c}\left(l_{6}+l_{5}+l_{4}\right)=0.175 m
\end{gathered}
$$

For Fig. 1(a):

$$
\begin{gathered}
l_{7}=l_{3}=0 \mathrm{~m} ; \\
l_{8}=l_{6}=L_{1} ; \\
l_{4}=l_{2}=L_{2} ; \\
L_{1}, L_{2} \in[0.01 \mathrm{~m}, 0.046 \mathrm{~m}] ; \\
d_{8 \_l}, d_{2 \_0} \in[0.0005 \mathrm{~m}, 0.032 \mathrm{~m}] ; \\
t \in[0.0006 \mathrm{~m}, 0.01 \mathrm{~m}] .
\end{gathered}
$$

For Figs. 1(b), and (c):

$$
l_{7}+l_{5}+l_{3}=L \in[0.083 \mathrm{~m}, 0.155 \mathrm{~m}]
$$




$$
T_{m n}=\Theta_{m n}-\frac{\left[\Theta_{m 3}-j \Theta_{m 4} \tan \left(k_{0} l_{b}\right)\right]\left[\Theta_{4 n}+j \Theta_{3 n} \tan \left(k_{0} l_{a}\right)\right]}{\Theta_{43}-j \Theta_{44} \tan \left(k_{0} l_{b}\right)+j \tan \left(k_{0} l_{a}\right)\left[\Theta_{33}-j \Theta_{34} \tan \left(k_{0} l_{b}\right)\right]}, \quad m, n=1,2 ;
$$

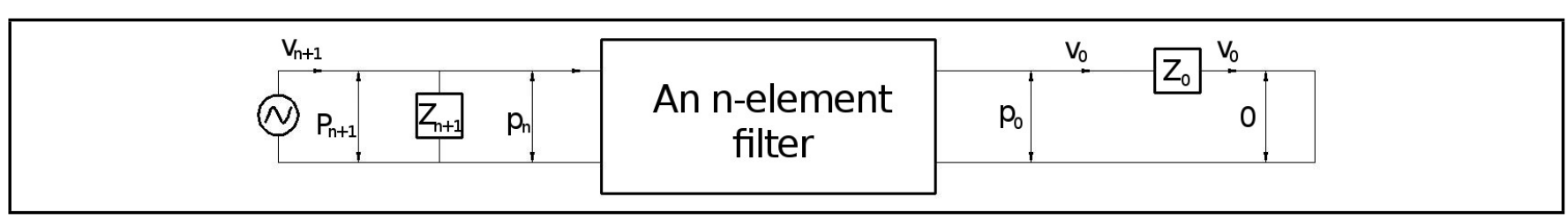

Figure 7. A schematic of the flow network for a one-dimensional pulsation attenuator.

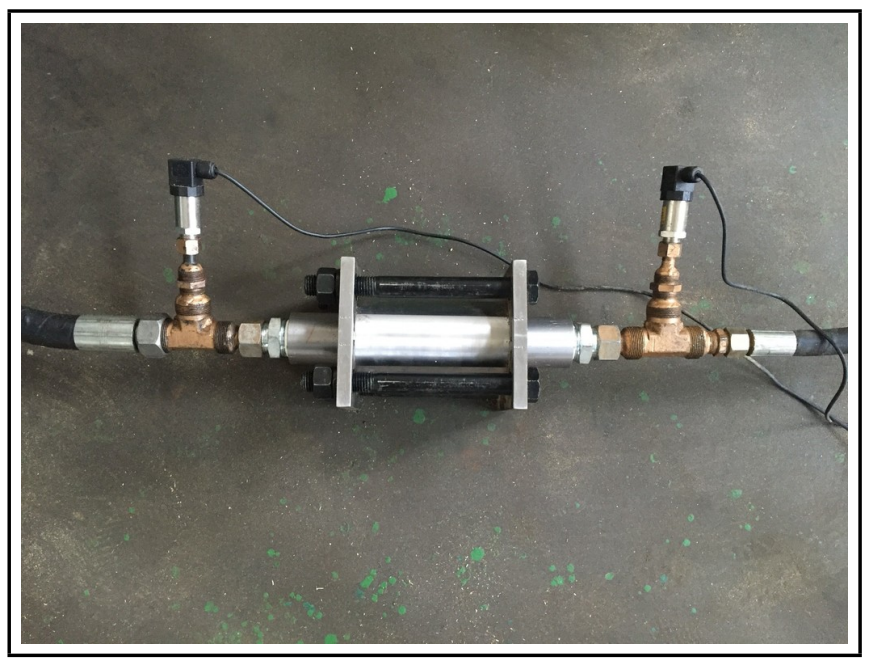

Figure 8. The experimental device of hydraulic suppressor.

\subsection{Mathematical Model Results and Predictions}

The variations of the parameters which affect the performance of the configurations of Figs. 1 (a), (b), (c) are studied in this chapter. For a double-tuned extended-tube chamber (DTETC) with above dimensions, ${ }^{12}$ the IL (as shown in Fig. 9) was compared to those of Figs. 1(a), (b), and (c). The frequency bands of most servo valves and servo systems were below $2000 \mathrm{~Hz},{ }^{14}$ therefore, the pressure pulsation that we were interested in could be limited to it. The signal which was higher than $2000 \mathrm{~Hz}$ may not be considered in this paper, for it did not interfere with the servo system. To a large extent, the IL depended on the geometry of the attenuator.

As seen from Fig. 9, the overall matching was reasonably good for the frequency domain of interest. Because the cut-off frequency of a circular tube was given by: ${ }^{13}$

$$
f_{c o}=\frac{1.84}{\pi} \frac{c_{0}}{D}=0.5857 \frac{c_{0}}{D}
$$

That is, just below $12 \mathrm{kHz}$, which was the cut-off frequency for the first higher mode for the configurations used in the experiments. The experimental device and sensitivity of Fig. 1(a) to variations in extended length is shown in Fig. 10 and Fig. 11, where the left and right extended lengths were identical (only $L_{1}$ is varied and made equal to $L_{2}$ ). The insertion loss was greater for the hydraulic noise suppressor with a lower extended length at frequency $<2000 \mathrm{~Hz}$. Increasing the length of the extended tube shifted the peaks of the insertion loss to lower frequencies. Comparing Fig. 9 and Fig. 11 gave that the

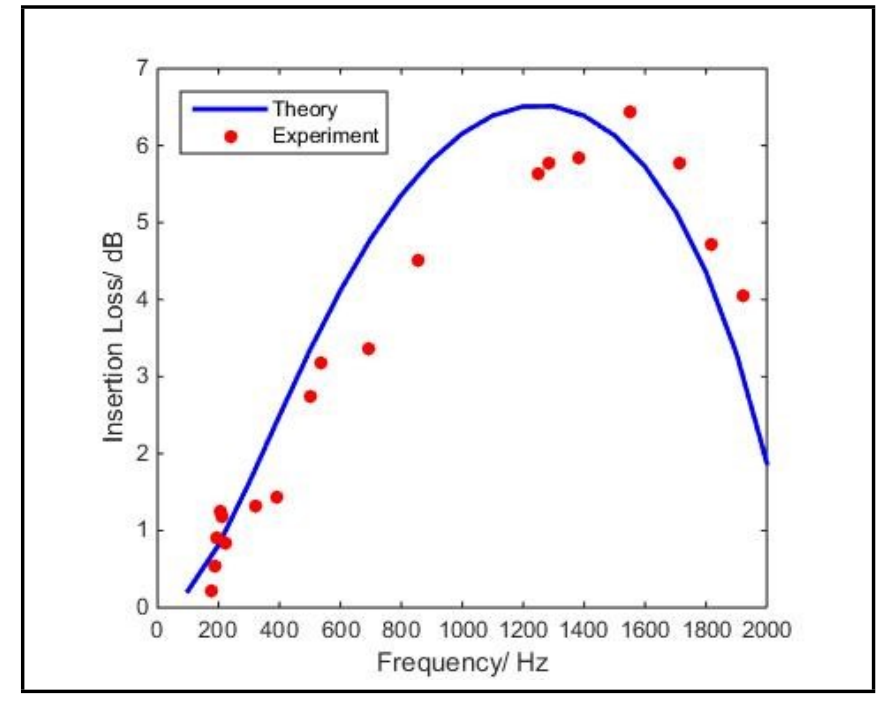

Figure 9. Fluid acoustic properties of DTETC theory versus experiment.

configuration of Fig. 1(a) had better acoustic attenuation properties during the frequency of interest $(0-2000 \mathrm{~Hz})$.

Figure 12 and Fig. 13 show the experimental device and the effect of the extended length of conical tube on the insertion loss characteristics $\left(L_{1} \neq L_{2}\right)$. The length of the end cavities contributed to the resonant peaks, since they, together with the conical tubes, constituted approximately a quarter-wave resonator. It was well-known that the resonator cavity can be represented at the junction by an equivalent impedance, which was inversely proportional to the extended length and the homologous area. This explained the shift observed in Fig. 11 and Fig. 13.

The effect of the minor diameter of the conical tube is shown in Fig. 14 ( $L_{1}$ and $L_{2}$ were retained the same). With the decrease of the minor diameter, it could be seen as an increase in the diameter of the expansion chamber inversely. The presence of the expansion chamber resulted in a simple expansion chamber behaviour. The troughs for the configuration of Fig. 1(a) appeared at frequency intervals:

$$
f=\frac{c_{0}}{2 l_{5}} \approx 8434 \mathrm{~Hz}
$$

(as shown in Fig. 14). A decrease in the minor diameter of the conical tube shifted the peaks and troughs to lower frequencies. Figure 14 also shows that the insertion loss for the structure of Fig. 1(a) increased with a decrease in the minor diameter of the conical tube during the research frequency band of $10000 \mathrm{~Hz}$. As the slope of the conical tube increased, the expansion chamber behaviour became more pronounced. 


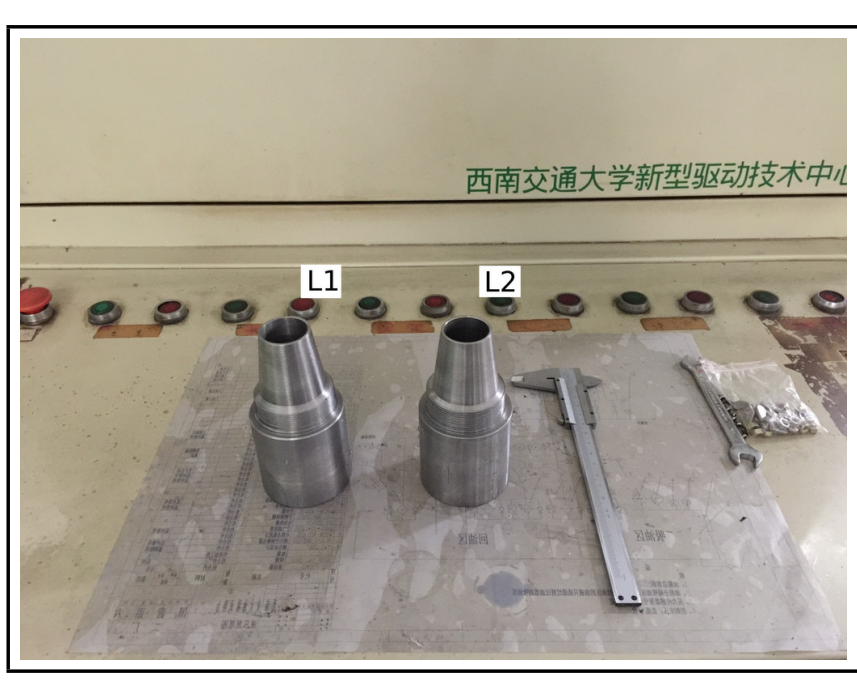

Figure 10. The experimental device of Fig. 1(a) $L_{1}=L_{2}=0.046 \mathrm{~m}$.

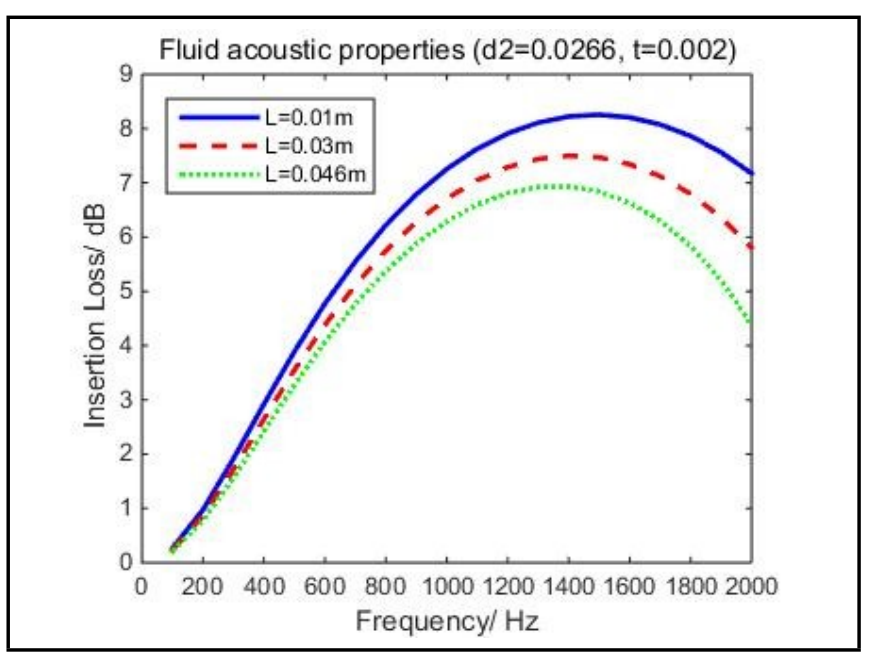

Figure 11. Effect of the extended length of one of the conical tubes on the performance of Fig. 1(a) theory versus experiment. $t=0.002 \mathrm{~m}, d_{8-l}=$ $d_{2 \_0}=0.0266 \mathrm{~m}$, and $M=0$.

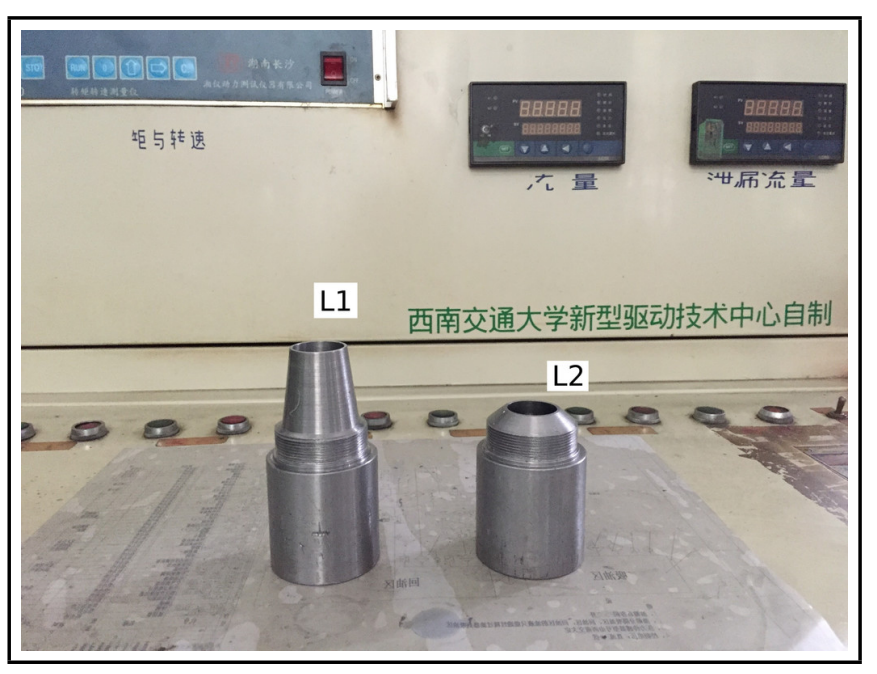

Figure 12. The experimental device of Fig. 1(a) $L_{1}=0.046 \mathrm{~m}, L_{2}=0.01 \mathrm{~m}$.

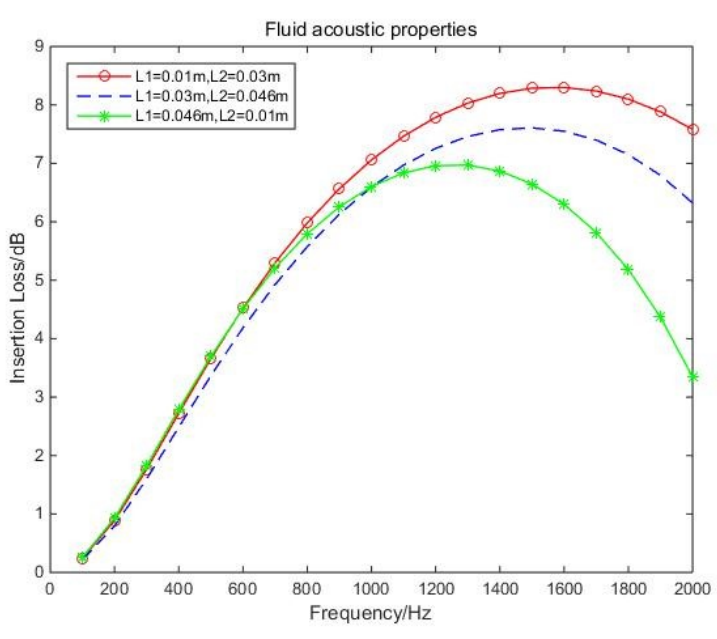

Figure 13. Effect of the extended length of conical tube on the performance of Fig. 1 (a) theory versus experiment. $t=0.002 \mathrm{~m}, d_{8 \_l}=d_{2 \_0}=0.0266 \mathrm{~m}$, and $M=0$.

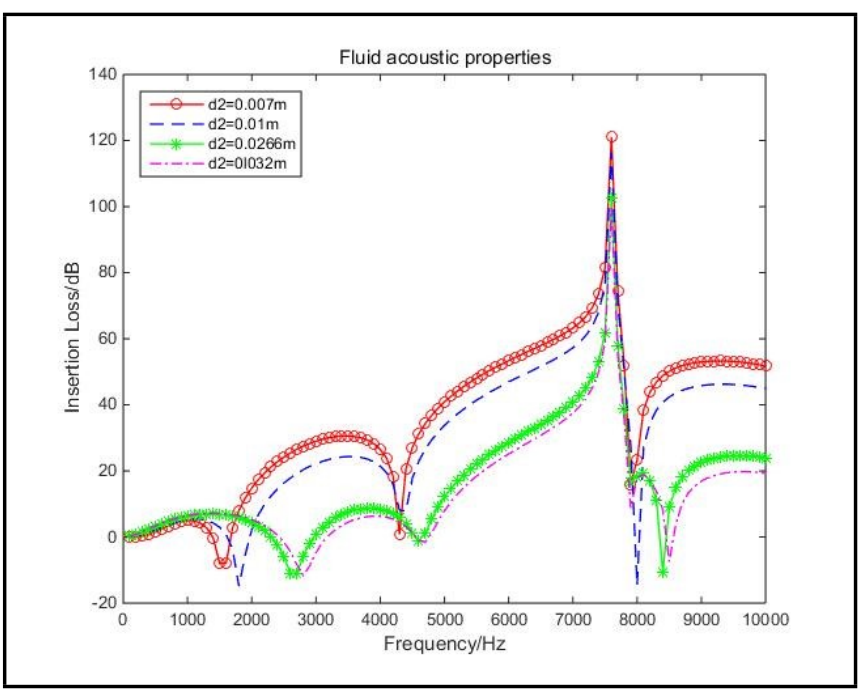

Figure 14. Frequency interval for the structure of Fig. 1(a). $d_{8 \_l}=d_{2 \_0}=d_{2}$, $L_{1}=L_{2}=L=0.046 \mathrm{~m}, t=0.002 \mathrm{~m}$, and $M=0$.

Figure 15 shows the effect of the thickness of the conical tube. With the decrease of the thickness of conical tube, the effect to the IL characteristics became smaller. A change in wall thickness in the 1-D model would result in a negligible change in the cross-sectional areas of the annular cavity and hence the area ratio. ${ }^{17}$ This would not result in lateral shifting of the peaks of the Fig. 1(a), as shown in Fig. 15.

The effect of the cross-sectional shape of the expansion chamber on the performance of Fig. 1(a) is shown in Fig. 16. Obviously, on the constraint of the interested frequencies $(<2000 \mathrm{~Hz})$, the IL characteristics of circular duct were better than others.

The experimental device and the sensitivity of Fig. 1(b) to variations in extended length of perforated tube is shown in Fig. 17 and Fig. 18. Within the interested frequency of $2000 \mathrm{~Hz}$, decreasing the extended length of the perforated tube shifted the troughs of insertion loss to lower frequencies.

The effect of increase in the slope of the conical tube is shown in Fig. 19 and Fig. 20. At lower frequencies, the 


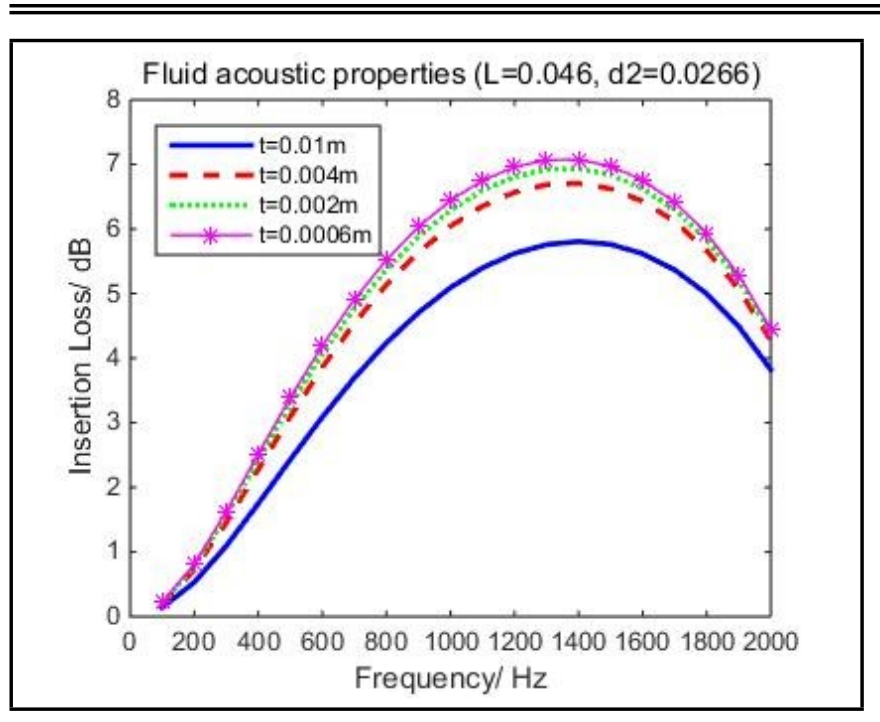

Figure 15. Effect of the thickness of one of the conical tubes on the performance of Fig. 1(a) theory versus experiment. $d_{8 \_l}=d_{2 \_}=d_{2}=0.0266 \mathrm{~m}$, $L_{1}=L_{2}=L=0.046 \mathrm{~m}$, and $M=0$.

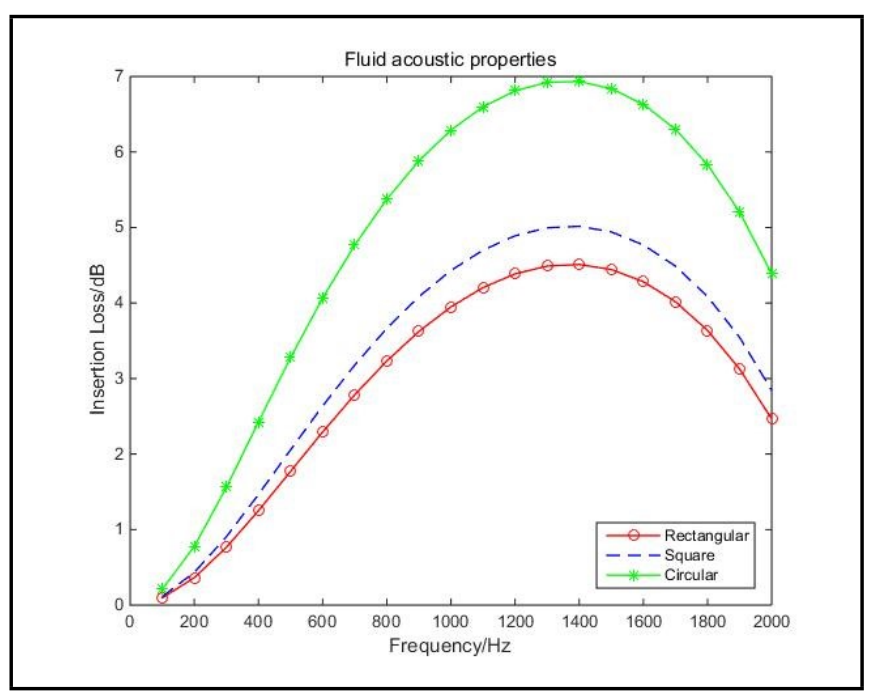

Figure 16. Effect of the cross-section shape of the expansion chamber on the performance of Fig. 1(a). $d_{8 \_l}=d_{2 \_0}=d_{2}=0.0266 \mathrm{~m}, L_{1}=L_{2}=$ $L=0.046 \mathrm{~m}, t=0.002 \mathrm{~m}$, and $M=0$; For Rectangular: $a=0.067 \mathrm{~m}$, $b=0.04 \mathrm{~m}$; For Square: $a=b=0.054 \mathrm{~m}$; For Circular: $d=0.068 \mathrm{~m}$.

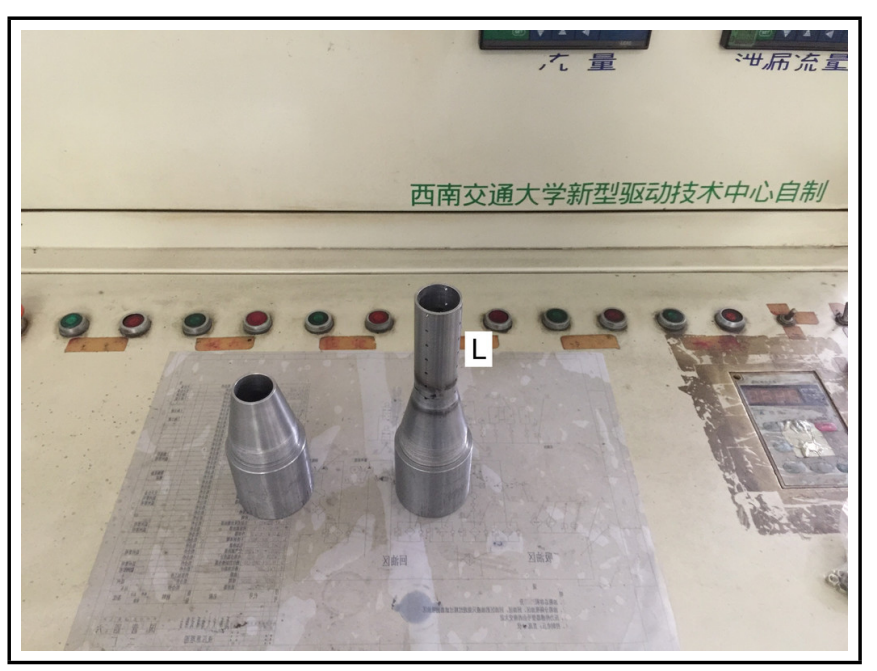

Figure 17. The experimental device of Fig. 1(b) $L=0.083 \mathrm{~m}$.

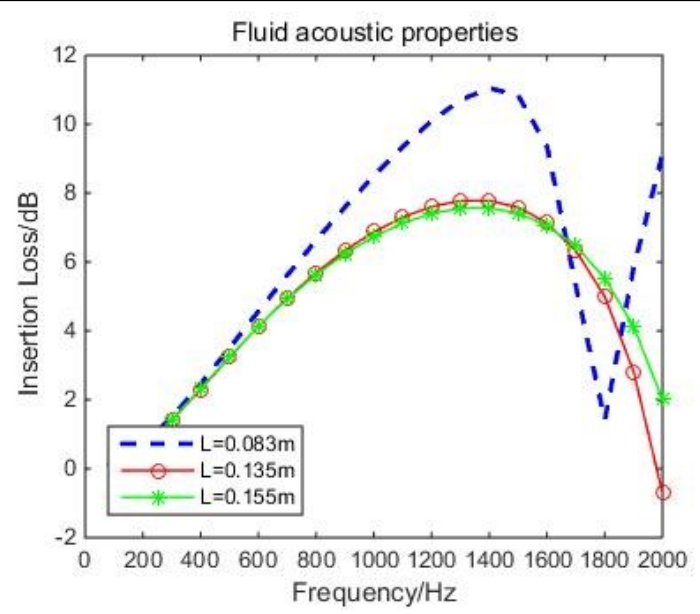

Figure 18. Effect of the extended length of perforated tube on the performance of Fig. 1(b) theory versus experiment. $d_{8 \_l}=d_{2 \_0}=d_{2}=0.0266 \mathrm{~m}$, $d h=0.002 \mathrm{~m}, t=0.002 \mathrm{~m}, \sigma=1 \%$ and $M=0$.

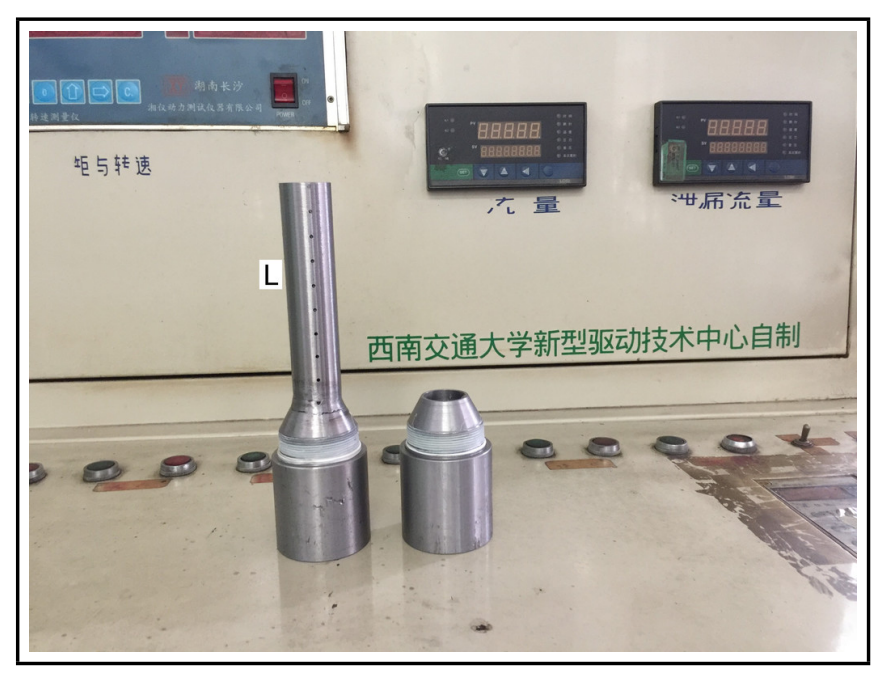

Figure 19. The experimental device of Fig. 1(b).

Helmholtz behaviour became more and more vital. Since the Helmholtz resonance frequency was inversely proportional to the square root of cavity area under a given length, the resonant peaks shifted to lower frequencies with the increase in the slope of the conical tube.

The effect of the hole diameter of the perforated tube of Fig. 1(b) is shown in Fig. 21. Notwithstanding the peak that the hole diameter was $0.006 \mathrm{~m}$ exceeds others, the slope was steeper when the frequency was $<2000 \mathrm{~Hz}$. Consequently, a conclusion that hole diameter in perforated tubes should not be too small in the hydraulic suppressor design could be drawn.

The effect of the porosity of the perforated tube is shown in Fig. 22. Increasing the porosity shifted the peak and trough of the insertion loss to higher frequencies. Sullivan's empirical formula was used for the perforation impedance in these predictions. ${ }^{1}$ With the increase in porosity, the effect to IL became smaller and when the porosity reached $20 \%$, which increased gradually, the effect was marginal. Consequently, for a hydraulic muffler designer, the porosity of the perforated tube should not be too large.

It was shown that the transmission loss (TL) curve of a concentric tube resonator (CTR) used in the air silencers could be 


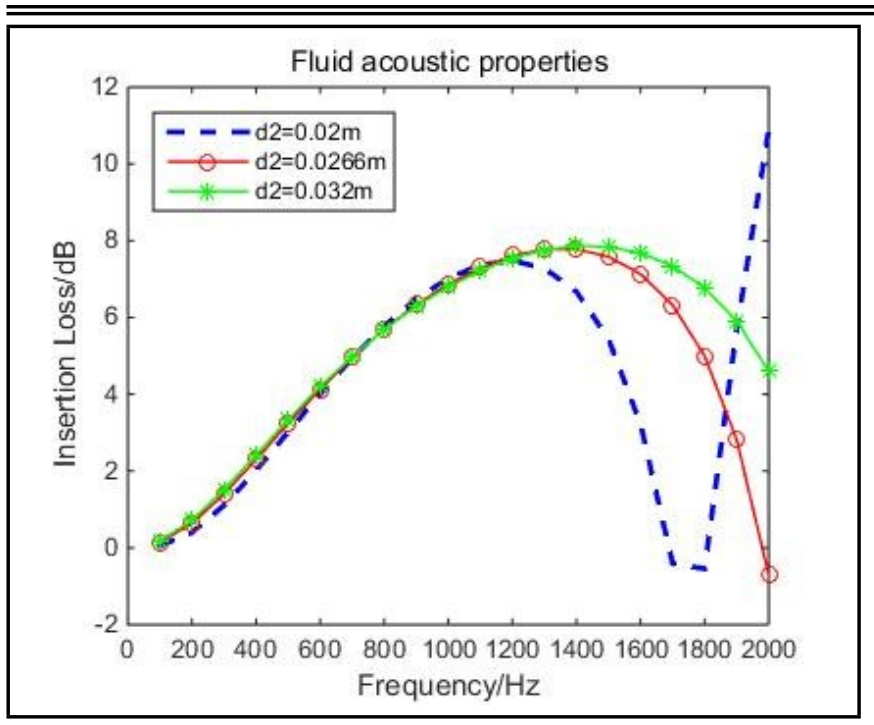

Figure 20. Effect of the minor diameter of the conical tube on the performance of Fig. 1(b) theory versus experiment. $L=0.135 \mathrm{~m}, d h=0.002 \mathrm{~m}$, $t=0.002 \mathrm{~m}, \sigma=1 \%$, and $M=0$.

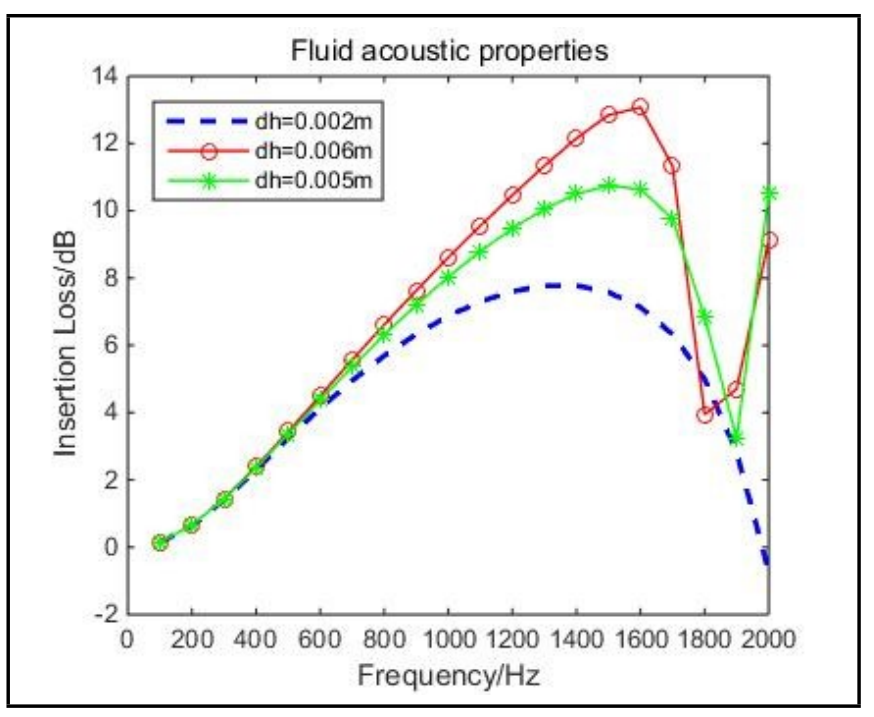

Figure 21. Effect of the hole diameter of the perforated tube on the performance of Fig. 1(b). $L=0.135 \mathrm{~m}, d_{2}=0.0266 \mathrm{~m}, t=0.002 \mathrm{~m}, \sigma=1 \%$, and $M=0$.

lifted by proper tuning of the extended unperforated lengths. ${ }^{15}$ CTRs which were used in the hydraulic suppressors are simulated in Fig. 23. It was shown that unperforated length had only a marginal effect on the IL characteristics, which was totally different from the CTR used in the air silencers. The difference between the CTR and the configuration of Fig. 1(b) was the gradual area structure that was used. The IL characteristics between these structures are shown in Fig. 24. The presence of the conical tube unit shifted the peaks and troughs of the CTR to lower frequencies; the effect, however, was marginal. With the increase in the slope of the conical tube, the IL characteristics at lower frequencies became better. Through the use of the optimization algorithm, a broad-spectrum hydraulic muffler for the configuration of Fig. 1(b) may be put forward.

Figure 25 shows the effect of the cross-sectional shape of the expansion chamber on the performance of the configuration of Fig. 1(b). On the constraint of $2000 \mathrm{~Hz}$, the peak of IL for circular shape exceeded the others, however the effect was

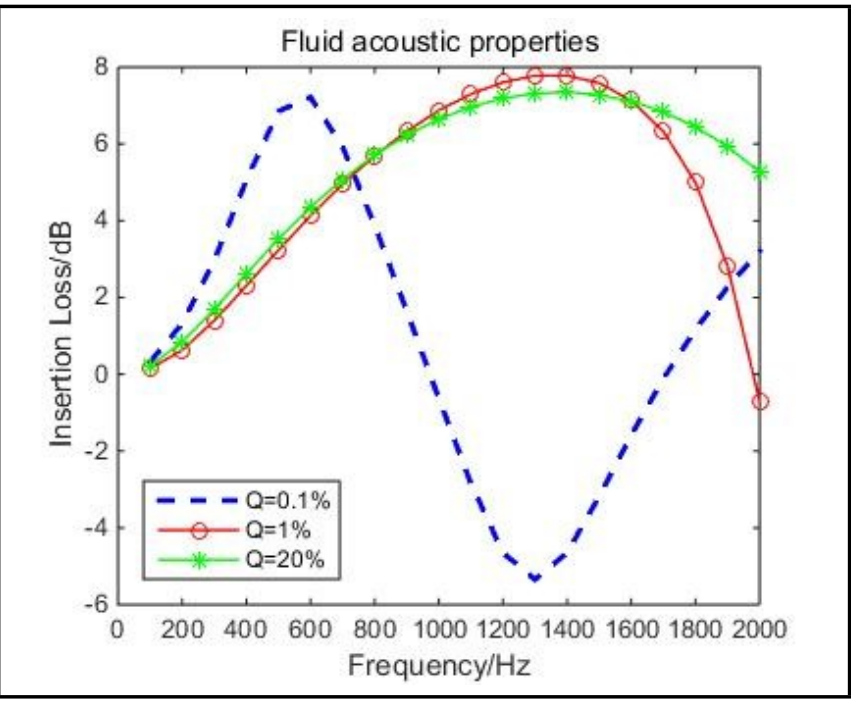

Figure 22. Effect of the porosity of the perforated tube on the performance of Fig. 1(b) theory versus experiment. $L=0.135 \mathrm{~m}, d h=0.002 \mathrm{~m}, t=0.002 \mathrm{~m}$, $M=0$, and $d_{2}=0.0266 \mathrm{~m}$.

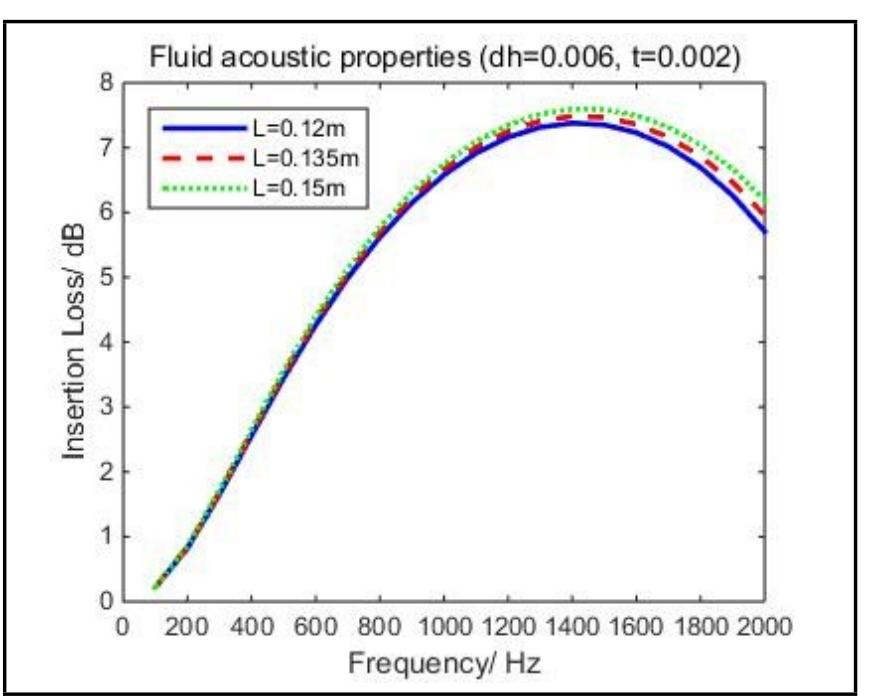

Figure 23. Effect of the extended unperforated lengths on the performance of CTR.

marginal.

The effect of the slope of the conical tube for the configuration of Fig. 1(c) is shown in Figs. 26 and 27. Decreasing the minor diameter of the conical tube shifted the peak and trough to lower frequencies. On the constraint of the same structure size, comparing the configuration of Fig. 1(b) and Fig. 1(c) shows that the insertion loss characteristics of Fig. 1(b) better than Fig. 1(c).

The effect of the extended length of the perforated tube is shown in Fig. 28. Comparison the configuration of Fig. 1(b) with (c), on condition that the structure size was identical, the IL characteristics of Fig. 1(b) is better than Fig. 1(c).

The effect of the cross-sectional shape of expansion chamber for the structure of Fig. 1(c) is shown in Fig. 29. The IL characteristics of circular chamber was better than other shapes, on condition that the structure size was the same, however, the effect was marginal. 


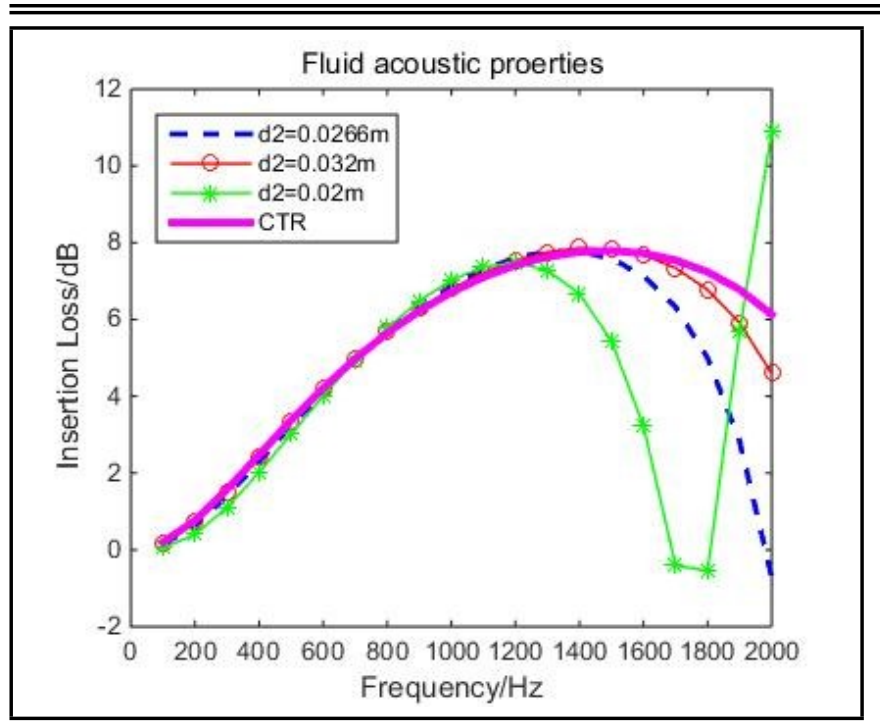

Figure 24. Comparison of theory prediction with experiment for the configuration of Fig. 1(b) and the concentric tube resonator (CTR) on the constraint of the same structure size. $L=0.135 \mathrm{~m}, d h=0.002 \mathrm{~m}, t=0.002 \mathrm{~m}, Q=1 \%$, and $M=0$.

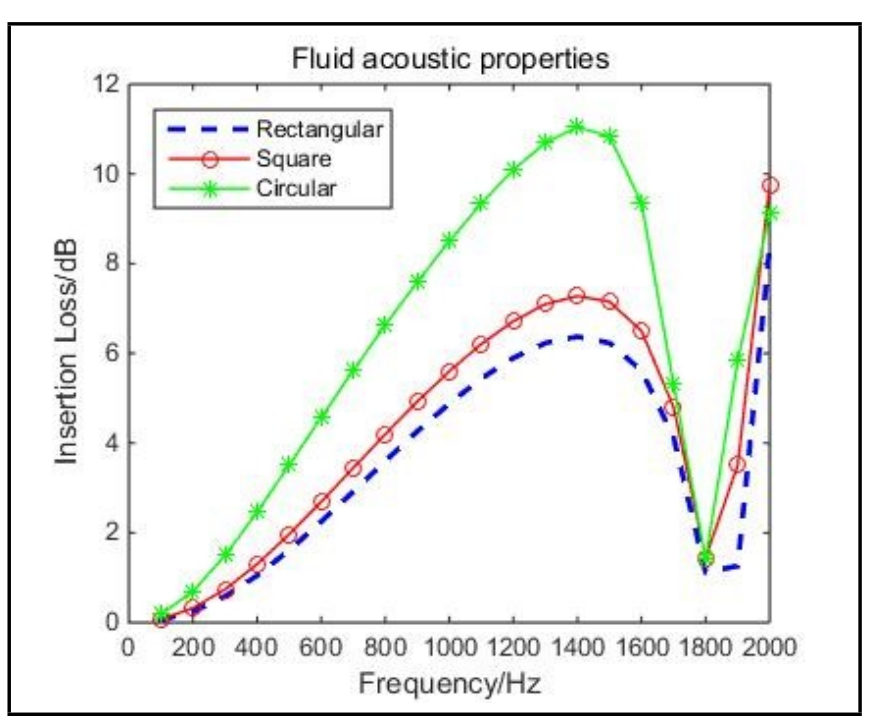

Figure 25. Effect of the cross-sectional shape of the expansion chamber on the performance of Fig. 1(b). $L=0.083 \mathrm{~m}, d h=0.002 \mathrm{~m}, t=0.002 \mathrm{~m}, Q=1 \%$, $M=0$, and $d_{2}=0.0266 \mathrm{~m}$. For Rectangular: $a=0.067 \mathrm{~m}, b=0.04 \mathrm{~m}$; For Square: $a=b=0.054 \mathrm{~m}$; For Circular: $d=0.068 \mathrm{~m}$.

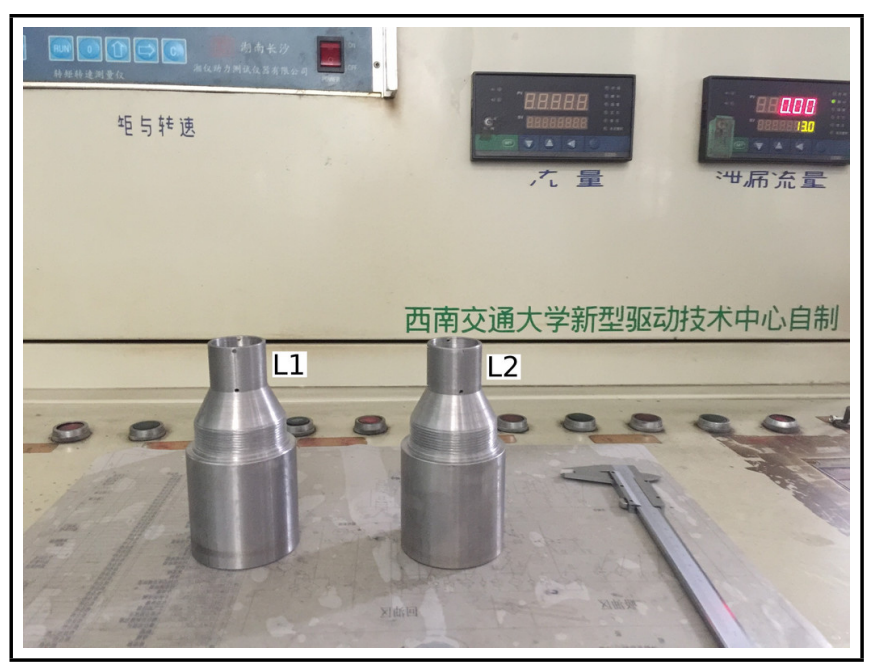

Figure 26. The experimental device of Fig. 1(c) $L_{1}=L_{2}=0.026 \mathrm{~m}$.

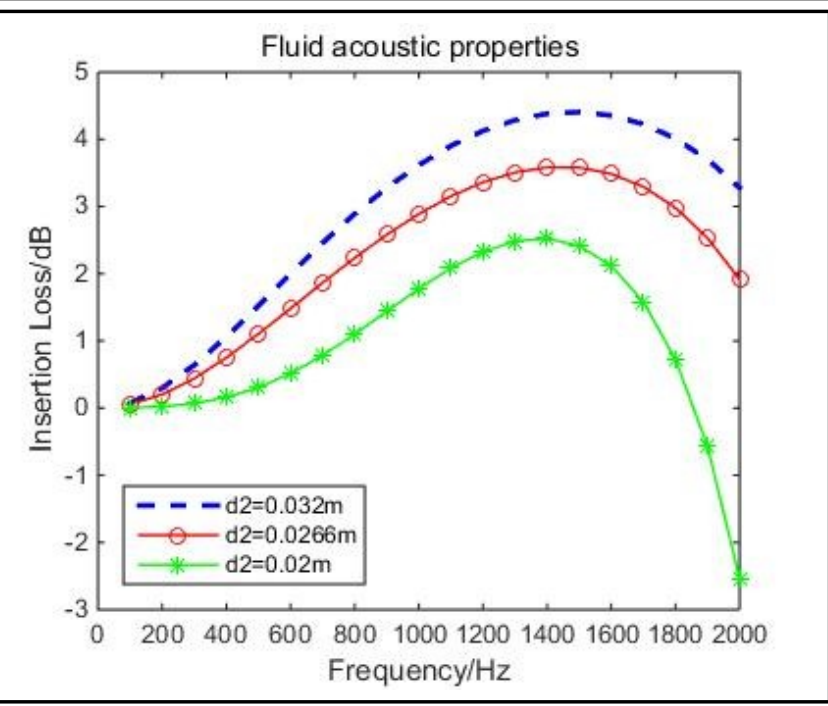

Figure 27. Effect of the slope of the conical tube on the performance of Fig. 1(c) theory versus experiment. $l_{7}=l_{3}=0.026 \mathrm{~m}$, and $M=0$, $L=0.135 \mathrm{~m}, d h=0.002 \mathrm{~m}, t=0.002 \mathrm{~m}, Q=1 \%$.

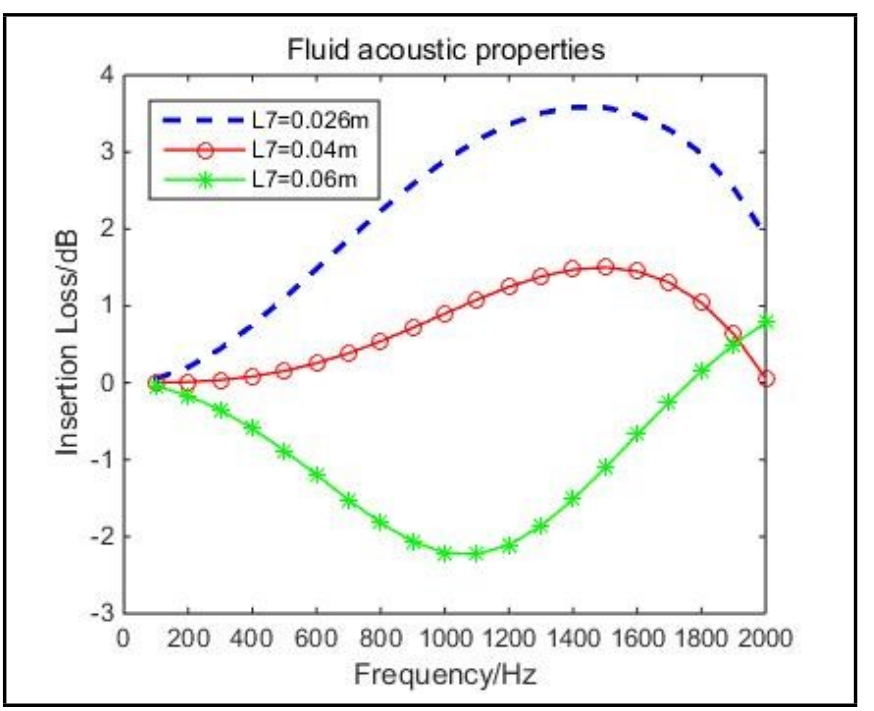

Figure 28. Effect of the extended length of perforated tube on the performance of Fig. 1(c). $L=0.135 \mathrm{~m}, d h=0.002 \mathrm{~m}, t=0.002 \mathrm{~m}, Q=1 \%, l_{7}=l_{3}$, $d_{2}=0.0266 \mathrm{~m}$, and $M=0$.

\section{CONCLUSIONS}

A plane wave one-dimensional approach is presented to analyse these improved hydraulic mufflers with extended necks. Theoretical and experimental results are compared for a fabricated prototype of hydraulic noise suppressors. The physical principles of noise reduction are the same as for air, however, the much higher sound speed of hydraulic oil makes creating compact noise control devices difficult. This paper introduces three improved hydraulic muffler configurations, using conical tube units that can shift resonance frequency and change insertion loss characteristics without changing the cavity volume, which increases the apparent volume of the device. Comparing with the double-tuned extended tube chamber (DTETC) and the concentric tube resonator (CTR) muffler, modification of the neck shape and adding perforation to the extended neck may be effective ways to control the resonance frequency and IL behaviour. Specifically, a conclusion 


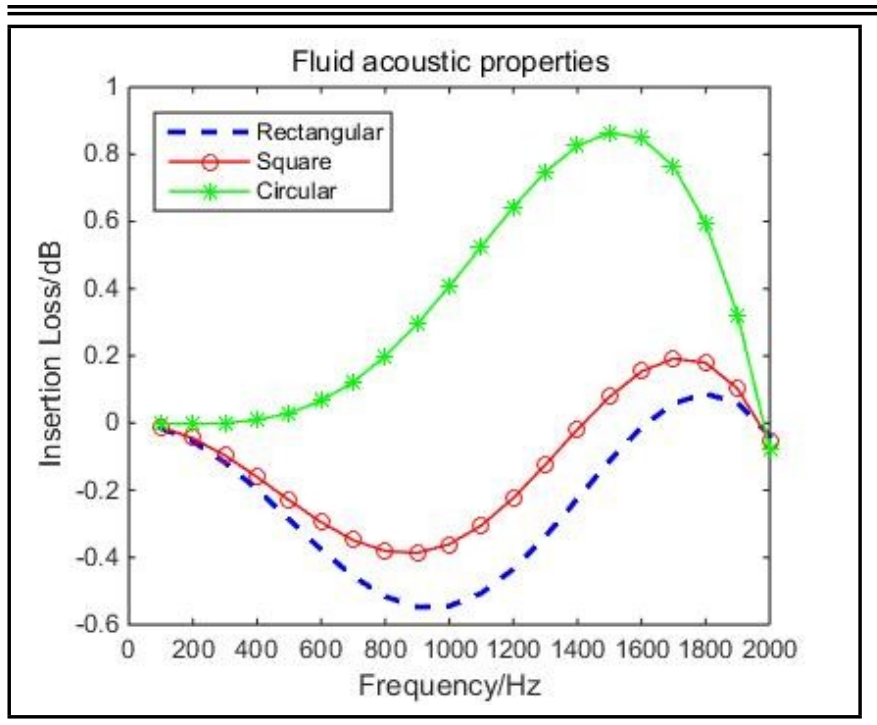

Figure 29. Effect of the cross-sectional shape of the expansion chamber on the performance of Fig. 1(c). $L_{1}=L_{2}=0.046 \mathrm{~m}, d h=0.002 \mathrm{~m}, t=0.002$, $Q=1 \%, d_{2}=0.0266 \mathrm{~m}, l_{7}=l_{3}=0.02 \mathrm{~m}$, and $M=0$. For Rectangular: $a=0.067 \mathrm{~m}, b=0.04 \mathrm{~m}$; For Square: $a=b=0.054 \mathrm{~m}$; For Circular: $d=0.068 \mathrm{~m}$

that hole diameter in perforated tubes should not be too small in the hydraulic suppressor design can be drawn in this paper, that is to say, a microperforated-panel which is widely used in the gas silencer design is not applicable for hydraulic mufflers.

\section{REFERENCES}

1 Sullivan, J. W. and Crocker, M. J. Analysis of concentric tube resonators having unpartitoned cavities, Journal of the Acoustical Society of America, 64, 207-215, (1978). https://dx.doi.org/10.1121/1.381963

2 Munjal, M. L., Narayana Rao, K., and Sahasrabudhe, A. D. Aeroacoustic analysis of perforated muffler components, Journal of Sound and Vibration, 114 (2), 173-188, (1987). https://dx.doi.org/10.1016/S0022-460X(87)80146-3

3 Munjal, M. L. Acoustics of ducts and mufflers (second edition), Wiley-Interscience, New York, (2014).

4 Shapiro, A. H. The dynamics and thermodynamics of compressible fluid flow, II, The Ronald Press, New York, (1954).

5 Gogate, G. R., and Munjal, M. L. Analytical and experimental aeroacoustic studies of open-ended three-duct perforated elements used in mufflers, Journal of the Acoustical Society of America, 97 (5), 2919-2927, (1995). https://dx.doi.org/10.1121/1.411858

6 Selamet, A. and Easwaran, V. Three-pass mufflers with uniform perforations, Journal of the Acoustical Society of America, 105 (3), 1548-1562, (1999). https://dx.doi.org/10.1121/1.426694
7 Sullivan, J. W. A method of modeling perforated tube muffler components. I: theory, Journal of the Acoustical Society of America, 66, 772-778, (1979). https://dx.doi.org/10.1121/1.383679

${ }^{8}$ Sullivan, J. W. A method of modeling perforated tube muffler components.: applications, Journal of the Acoustical Society of America, 66 (3), 779-788, (1979). https://dx.doi.org/10.1121/1.383680

9 Peat, K. S. A numerical decoupling analysis of perforated pipe silencers, Journal of Sound and Vibration, 123, 199-212, (1988). https://dx.doi.org/10.1016/S0022$460 \times(88) 80106-8$

10 Munjal, M. L., Sreenath, A. V., and Narasimhan, M. V. Velocity ratio in the analysis of linear dynamical systems, Journal of Sound and Vibration, 26 (2), 173-191, (1973). https://dx.doi.org/10.1016/S0022-460X(73)80230-5

11 Selamet, A., and Lee, I. Helmholtz resonator with extended neck, Journal of the Acoustical Society of America, 113 (4), 1975-1985, (2003). https://dx.doi.org/10.1121/1.1558379

12 Munjal, M. L., Galaitsis, A. G., and Ver, I. L. Passive Silencers, Noise and Vibration Control Engineering (eds. I. L. Ver and L. L. Beranek), John Wiley \& Sons, Inc., New York, (2006).

13 Eriksson, L. J. Higher-order mode effects in circular ducts and expansion chambers, Journal of the Acoustical Society of America, 68 (2), 545-550, (1980). https://dx.doi.org/10.1121/1.384768

14 Luo, Z. C. Fluid network theory, China Machine Press, Beijing, (1988).

15 Ramya, E. and Munjal, M. L. Improved tuning of the extended concentric tube resonator for wide-band transmission loss, Noise Control Engineering Journal, 62 (4), 252263, (2014). https://dx.doi.org/10.3397/1/376225

16 Marek, K. A., Gruber, E. R., and Cunefare, K. A. Linear multimodal model for a pressurized gas bladder style hydraulic noise suppressor, International Journal of Fluid Power, 14 (2), 5-16, (2013). https://dx.doi.org/10.1080/14399776.2013.10781071

17 Chaitanya, P. and Munjal, M. L. Effect of wall thickness on the end corrections of the extended inlet and outlet of a double-tuned expansion chamber, Applied Acoustics, 72 (1), 65-70, (2011). https://dx.doi.org/10.1016/j.apacoust.2010.09.001 